\title{
Sütçü ineklerde erken postpartum dönemde ovaryum aktivitesinin uyarılması üzerine çalışmalar
}

\author{
Mustafa KAYMAZ \\ Ankara Üniversitesi, Veteriner Fakültısi, Doğum ve Jinekoloji Anabilim Dalı, Ankara
}

\begin{abstract}
Özet: Bu çálışmada, erken postpartum dönemde GnRI, PGF $\alpha$. betamimetik ve betablokörlerin kullanmmmun reproduktif per formansia etkileri araștırıldı. Çalıșma ve kontrol grubunu oluş̧uran toplam 50 baș inek 5 gruba ayrıldı. Grup l'i (Kontrol) postpartum (pp) 15.34. giinlerde bulunan inekler oluşturdu. Bu gruba herhangi bir uygulama yapilmad. Grup II. III, IV ve Ve postpartum 15

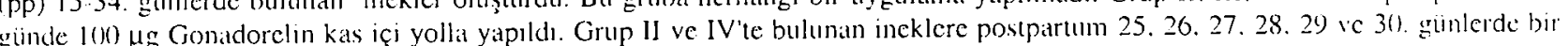
betamimetik preparat olan Bamethane sulphate (BS) $1 \mathrm{mg} / \mathrm{kg}$ dozunda intravenöz yolla enfüze edildi. Bu lygulamityl likiben Grup Il ve lll'deki hayvanlara postpartum 31. günde Cloprostenol kas içi yolla enjekte edildi. Grup IV ve V'te bulunan hatyvanlatra isc

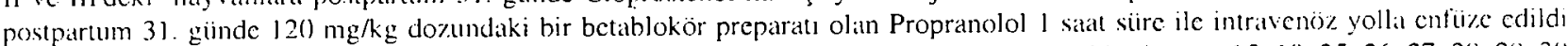
Kan progestcron değerlerinin saptammass amacl ile Grup I (kontrol). II ve IV'de bulunan incklerden pp. 15. 18, 25. 26. 27. 28. 29, 30) 31 ve 34 . gänlerde kan örneklcri alınd. Grup II ve IV'de BS uygulamasından önce ve 1 satat sonra ikinci kan örnckleri alındı. Grup IIl ve V'den pp 15. 18,31 ve 34. günlerde kan örnekleri toplanırken Grup V'de pp 31. güunde Propranolol uygulamasinn lakiben 1 satill sonra kan ömeğ alınd. Postpartum 34. günden sonra östrus gösteren tiim hayvanlar tohumbandı. Çalışmada, bu/alğglama-ilk ostrus

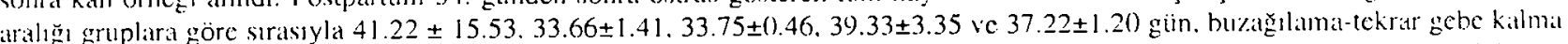
aralı.

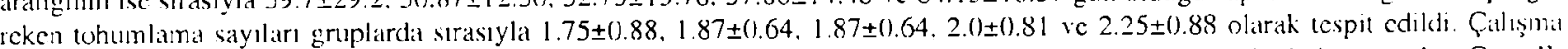
süresince gebe kalan incklerin oranlar Grup I. II. III. ve V'de \%80, Grup IV'de \%70), ilk tohumlamada gebe kalma orantarn Grup II. III. IV ve V'de \%20), Grup l'de (Kontrol) \%4(), ikinci tohumlamada gebe kalma oranları Grup I ve V'de \%20), Grup II ve III'de \%5() ve Grup IV'de \%30. son olarak uiçüncii tohumlamada gebe kalma oranlan Grup I (Kontrol) ve IV'de \%20. Grup II ve III'de \%10 ve Grup V'de \% 4 () olarak saptandı. Ilk tohumlama oncesinde 1 I inekte anöstrus ve metritis tablosuyla karşılaşıldı. Betammimetik uygulanam gruplarda kan progesteron değcri, uygulanmayanlari oranla tüm çalışma süresince belirgin bir şekilde fäla bulundu. Betablukör ilä-

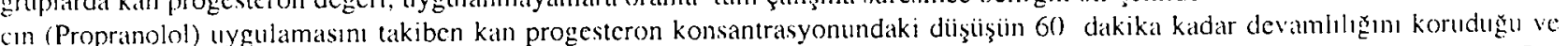

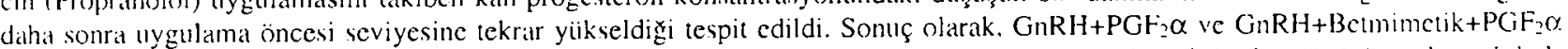
uygulamaları sonrasında elde edilen bulgular, bu kombinasyonların erken postpartum dönemde balı kriterler gö\%oniine alınarak kıl-

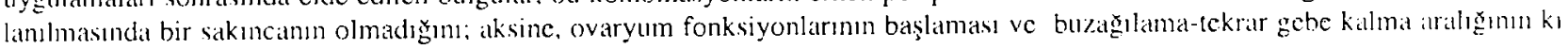
salulmassinda kullanılabileceğini göstermiş̧ir.
\end{abstract}

Anahtar kclimeler: Betablokör ve betamimetik ilaçlar, GnRH, PGF $\alpha$, postpartum dönem, siit ineği

\section{Studies on the induction of ovarian activity in the early postpartum period in dairy cows}

Summary: In this study, it was aimed to determine effects on the reproductive performance of the administration of GnRH. PGF O. beta-direnomimetic and betablockers in the early postpartum period in dairy cows. Fifty postpartum cows were divided into 5 groups. Group I $(n=10)$ was served as control. In Group II, III, IV and V, 100 $\mu \mathrm{g}$ GnRH (Gonadorelin. Ovarelin. DIF) was injected intramuscularly. On the 15 th days of postpartum (pp). In Group II and IV betaadrenomimetic drug (Bamethane sulphitte. BS. SICiMA) was infused ( $1 \mathrm{mg} / \mathrm{kg} / \mathrm{daty}$ ) intravenously between days $25-30 \mathrm{pp}$, and then on the day $31 \mathrm{st} 2 \mathrm{ml} \mathrm{PGF} 2 \alpha$ (Cloprosicnol $\mathrm{N}_{i 1}$ wath injected intramuscularly. In Group IV $(n=10)$ and $V(n=10), 120 \mu g / k g$ betablocker drug (Propranolol. P. SIGMA) Wass administered intravenously on the 31 st day of postpartum. In Group $V(n=10)$, GnRH was given intramuscularly 15 th day of $p p$ and $P$ was intused in one hour time via intravenously on the $31 \mathrm{st}$ day of pp. Blood samples were collected for progesterone insay on dilys 15. 18, 25, 26, 27, 28, 29,30 in Group I. II, IV. and especially in the Group II and IV blood samples were taken betore and I hour after BS infusions. In the Group III and $V^{\circ}$ samples were collected on days 15. 18. 31, 33, 34 pp and 1 hour before and $I$ hour al ter the Padministration (Day 3lst pp). Animals were artificially inseminated after postpartum 34th day. As a result of this study, the interval between parturition and first oestrus was determined as 41.22 $\pm 15.53,33.66 \pm 1.41,33.75 \pm 0.46,39.33 \pm 3.35$ and $37.22 \pm 1.20)$ davs, open period was determince as $59.7 \pm 29.2 .50 .87 \pm 12.30,52.75 \pm 13.78,57.86 \pm 14.48$ and $64.13 \pm 18.57$ days. the number of inscminations for each pregnancy was determincd as $1.75 \pm 0.88,1.87 \pm 0.64,1.87 \pm 0.64,2.0 \pm 0.81$ and $2.25 \pm 0.88$. respectively Pregnancy rates in group I. II, III. and V were $80 \%$ and in the Group IV $70 \%$. Pregnancy rates at first insemination were, $20 \%$ in group II. III. IV and V. and 40\% in Group I. Pregnancy rates at sccond inscmination were $20 \%$ in group I and V. $5(1) \%$ in group $I I$ athd III. $30 \%$ in the Group III. Pregnancy rates at third insemination were $20 \%$ in group I and IV. $10 \%$ in Group 11 and $40 \%$ in Group V. Totally II cows had anocstrus before first insemination and metritis. Blood progesterone concentrations significantly increased wilhin the 1 hour period after BS infusion. At the end of the first hour, progesterone concentrations decrealsed but not the preinjection values. The progesteron concentration was decreased after $P$ infusion and was protected these level approximately 60)-70) minutes and soon after was increased up to the preinfusion Icvel. It can be concluded that the administration of GnRH+betamimetic $+P G F, \alpha$ during the carly postpartum period coud be used because of the shortened of the parturition-first ocstrus interval and open period. H()vewer, based on this study the use of betablockers either with $\mathrm{GnRH}$ or GnRH+betamimetic infusions did not improve the fertility.

Kcy words: Betablockers, betamimetics, dairy cows, GnRH, $\mathrm{PGF}_{2} \alpha$, postpartum period 


\section{Giriş}

Yavru zarlarmmn atılmasindan sonra postpartum evrede bulunan uterus involüsyon sürecine girer. Involuisyon tekrar gebelik oluşumu için en uygun ortamı yaratma amacıyla oluşmaktadır (48).

Klinik gözlemlere ve rektal muayene bulgularnna göre uterus involüsyonu sütçü ineklerde 26-52. günde $(38.43)$ tamamlanırken, etçi ineklerdc 38-56. günde sona ermektedir. Involuisyonun ultrasonografi ile izlenmesi sonunda bu sürenin $41.5 \pm 5.8$ gün olduğu tespit edilmiştir (17).

Postpartum ovaryum aktivitesi ve uterus involüsyonu ile postpartum ilk östrus arasındaki süreyi yazarlar sütçü incklerde 30-76 gün, etçi ineklerde ise 40-68 gün olarak bildirmektedir $(4,15,38,43)$. Yapılan bir çalısmada ultrasonografi ile ovaryum fonksiyonlanı izlemmis ve postpartum ilk östrus $21.7 \pm 7.3$ gün tespit edilmiştir (17).

Sığırlara ostrus sikluslarının 12-16. gününde çiftleşme öncesi yüksck dozda $(100 \mu \mathrm{g})$ tek aplikasyon şeklinde uygulanan GnRH'nnn korpus luteum'dan salman progestcronda artışa neden olduğu ve kısa östrus sikluslarmmn eliminasyonu ile, sonraki ya da izleyen ösırusta gebe kalma oranını arttırdı 乌̆

Poslpartum 14-28. günler arasinda $25 \mathrm{mg}$ Dinoprost'un tck uygulamasının gebe kalma oranında belirgin bir gelişmeye neden olduğu da araştırıcılar tarafından destcklenmektedir (48).

Katekolaminlerin ovaryumdaki folliküllerin gelişne ve farklılaşnasında rolü olduğu belirginse de bunların ovulasyonda follikiiler ruptur ve korpus luteum fonksiyonu üzerindeki etkileri tam belirginlik kazanmamıştır. ()varyum damarlarının myojenik tonusunun katekolaminler tarafından düzenlendiği ve östrojenlerin ovaryum beyaz kas huicrelerinde adrenerjik reseptörleri artırdığı helirtilmektedir (10.46). Adrenerjik (scmpatik) sinir lifleri, kolineriik (parasempatik) sinir liflerine göre ovaryunda daha bol bulunmakla ve ovaryuma ovarian pleksustan ovaryum arteri ile beraber giren damarlarla ve suspensor ligament yolu ilc girncktcdirler $(26,44,46,49$, 50). Korpus lutcum'un yaşam süresi sırasında ihtiva ettiği $\beta$-adrenerjik reseptör konsantrasyonu gelişmemiş veya olgun Graaf follikuilünün granuloza hücrclerinin ihtiva cttiği yoğunluktan daha fazladır. Korpus hemorajikumun $\beta$ reseptör içeriğgi immature veya olgun granuloza hücrelerine göre $5-15 \mathrm{~kat}$ daha fazladır. Deksamethazon gibi hormonların $\beta_{1}$ alt tipinden $\beta_{2}$ alt tipine dönüşü gerçekleştirdiği bildirilmektedir $(36,40)$. Luteal doku adrenerjik stimuilasyona oldukça duyarlıdır (40).

Katekolaminlerin progesteron sckresyonu üzerindeki stimiile edici etkisi $\beta$-reseptörler ve c-AMP aktivasyonu yolu ile olnakta ve bu nedenle androjen biyosentczinin uyarılnıası $\beta$-adrencrjik stimülasyonla gerçekleşmektedir (26.28).

Memeli ovaryumu follikülün değişik gelişme dönemlerinde, follikül duvarında bulunan non-vaskuler adrenerijik sinirler yolu ile innerve edilirler (18).
Sempatomimetik ilaçlar bir diğ̣er adıyla ka tckolaminler, efektör organları adrenerjik reseptörler izerinden direk ve/veya indirek olarak etkileyen ve sempatik sinir stimuilasyonunun bu organlardaki ctkilcrini taklit eden ilaçlardır. Birçok türde ovaryuma ve korpus lutcuma ait B-rescptörlerin adrenalin ve noradrenalin gibi $B$ mimetik ilaçlar tarafından aktivasyonu inek. rat. tavşan. koyun, domuz gibi hayvanlarda adenilat siklaz enzimini aktive ederek progesteronun salınımına neden olmuştur $(25,27.35,37.50)$.

Adrenerjik reseptörler hücre menbranının dış yüzü üzcrinde yerleşmiş makromolekiillerdir. $A_{1}$ ve $B_{2}$ reseptör blokörii olan propranolol tüm kaltekolaminlere eşil derecede etki etmcktedir (19).

Beta-adrenerjik reseptörler, duyarlı hücrelerin membranının dış yüzünde yerleşmiş olan $(1,3,20)$ ve $\beta$ agonist ve antagonist maddeleri tanıyp onlarla geri dönüşümlü olarak birleşen noktalardır (20). Bu ilaçlar Badrenerjik reseptörleri geri döniş̧iinllii bir şckilde bloke ederek sinir stimuilasyonunun veya i\%oprenalin veya diğger 3-mimetik ilaçların çeşitli yaplar üzcrindeki etkilerini an tagonize ederler. Tün B.-adrenoreseptör bloke cdici ilą̧ lar katekolaminlerin ve diğer sempatomimctiklerin elkilerini ß-adrenerjik reseptörlerde yanş halinde bloke ederler (20). Propranolol lokal anestezik ilaçlar gibi eksitabl hücrelerin membranlannda sodyum kanallarm bloke edcrek membranı depolarizasyona karşı stabilize cder. (20,23). Yapılan bir çalışmada luteal evrede bulunan koyunlara uygulanan propranolol'in periferal progesteron konsantrasyonunu düşürdüğü. $\beta_{2}$-adrenerjik agonistlerinin (ritodrin, salbutamol) ise progesteron seviyesini arturdloğ tespit edilmiştir (49). Propranolol aym zamanda LH'unn progesteron sentezi üzerindeki stimüle colici etkisini de bloke etmiş ve bunun luteotrofik ve adrenerjik rescptörler arasında biyokimyasal bir bağlantı olduğu diişüuncesini or taya çıkartmıştır (16). Bir betareseptör blokörü olaı $\mathrm{Ca}$ razolol'un incklere uygulanmasindan sonra östrogen konsantrasyonunda bir azalmaya rastlanmiş, progesteron ve LH konsantrasyonlarında az niktarda bir y'ükselnte lespil cdilmiştir (25).

Katekolaminler preovulatör dönem içerisinde folliküler hücre farklılaşmasını uyanrken. ayrıca uvulasyon sırasında folliküler duvar kontraksiyon/relaksasyonunda da görev almaktadır (46). In vivo çalı̧̧malarda katekolaminler folliküler büyümeyi, ovulasyonu ie ovaryumun myojenik tonusunu değiştirmektedirler. Folliküiler steroidogenezis ve ovaryum kan akımmnn adrenerjik stimülasyonunun potansiyel ilişkisi değerlendirilmentiştir (46).

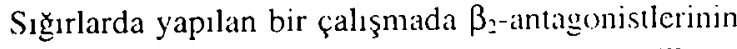
fertilite üzcrindeki etkisi araştırılmış ve postpartum ilk tohumlama zamannda yapilan tedavilerde sonucun iyi olmadığı bildirilmiştir. Tohumlamayı takihen uygulanan $\beta$ blokör ajan Carazolol uygulamasindan sonra gebe kalma oranın \%62.9 oranında, GnRH \%58.8 oranunda bulun muştur. En az iki kez tohumlanan hayvanlar veya in- 
fertilite tedavisi gören hayvanlar Carazolol veya $\mathrm{GnRH}$ sağıımından sonra daha yüiksek oranda gebe kalmışlardır (21).

Sunulan çalışmada, erken postpartum dönemde bulunan sütçï incklere $\mathrm{GnRH}, \mathrm{PGF}_{2} \alpha$ ve betamimetik ve betablokörlerin çeşitli alternatiflerle kullanılması ve bunlarm fertilite parametreleri üzerindeki ctkilcrinin gö $\%$ lenmesi amaçlandı.

\section{Materyal ve Metot}

$\mathrm{Bu}$ çalışma, Tarım Işletmeleri Genel Müdürlüğii (TIGEM) Karacabcy Tarm Işletmesi Müdürlügüunde bulunan 50) baş inek iizerinde yapıldı. Doğum sonrası 10-14. günlerinde yapilan rektal muayeneleri sonrasinda falışmaya alınacak 50 baş inek kesin olarak belirlendi. Inckler 10'ar başlık, biri kontrol olmak üzere 5 gruba ayrıldı ve sürüi içerisinde seçilebilecek şckilde işaretlendi.

Grup I, kontrol grubu olarak ayrildı ve bu gruptaki hayvanlara herhangi hir uygulama yapılmadı. Gruplara bölünen hayvanlardaki uygulamalar Tablo l'de özetlenmiştir. Grup II'yi oluşturan hayvanlara $(n=10)$ doğunu izleyen 15. güin $50 \mu \mathrm{g} / \mathrm{ml}$ Gonadorelin içeren GnRH preparatından (Ovarelin, DIF) $100 \mu \mathrm{g}(2 \mathrm{ml})$ kas içi yolla cnjekle edildi ve doğum sonrası $25,26,27,28,29$ ve 30 ginlerde intravenoiz yol ile $1 \mathrm{mg} / \mathrm{kg}$ dozunda Bamethane sulphate (SIGMA) uyguland. Doğumu izleyen 31. gün $236 \mu \mathrm{g} / \mathrm{ml}$ Cloprostenol sodyum içeren $\mathrm{PGF}_{2} \alpha$ analoğundan (Estrumate) 2 ml kas içi yolla enjekte edildi. Grup III, doğumu izleyen 15. giin $50 \mu \mathrm{g} / \mathrm{ml}$ Gonadorelin içeren GnRH preparatından 100 $\mu \mathrm{g}$ kas içi yolla enjekte edildi. Doğum sonrası 31. gün $2.36 \mu \mathrm{g} / \mathrm{ml}$ Cloprostenol $\mathrm{Na}$ içeren PGF2a analoğundan (Estrumate) $2 \mathrm{ml}$ kas içi yolla enjekıc cdildi. Grup IV'e doğum sonrasi 15 . gün 50 $\mu \mathrm{g} / \mathrm{ml}$ Gondorelin içeren GnRH preparatından $100 \mu \mathrm{g} / \mathrm{ml}$ kas içi yolla enjekte edildi. Ineklere doğun sonrasi 25 , $26,27.28,29$ ve 30 günlerde intravenöz yol ile $1 \mathrm{mg} / \mathrm{kg}$ dozunda Bamethane sulphate (SIGMA) uyguland. Hayvanlara doğum sonrası 31 günde $120 \mu \mathrm{g} / \mathrm{kg}(2 \mu \mathrm{g} / \mathrm{kg} / \mathrm{dak})$ dozunda 1 saat süre ile intravenöz yolla DL-Propranolol $\mathrm{HCl}$ (SIGM $\Lambda$ ) uyguland. Grup V'e ise. doğum sonrası 15. gün diğer gruplarda olduğu gibi $50 \mu \mathrm{g} / \mathrm{ml}$ Gonadorelin içeren GnRH preparatından $100 \mu \mathrm{g}$ kas içi yolla enjekte edildi, hayvanlara doğum sonrası 31. günde 120 $\mu \mathrm{g} / \mathrm{kg}(2 \mu \mathrm{g} / \mathrm{kg} / \mathrm{dak})$ dozunda 1 saat süre ile intravenö\% yolla DL-Propranolol HCl (SIGMA) uyguland.

Grup I'dcki (Kontrol) ineklerden doğumu izleyen $15,18,25,26.27,28,29,30,31$ ve 34 . günlerde. Grup Il'den doğumu izleyen $15,18.31,33.34$ ginlerde tek. $25,26,27,28,29,30$ günlerde ise uygulama öncesi ve 1 saat sonrası olmak ïzere iki kcz ayn yöntemle kan alındı. Grup III'te bulunan ineklerden doğunu izleyen 15, 18. 31,33 ve 34. günlerde kan alındı. Grup IV'leki inck. lerden ise doğum sonrası $15,18,33$ ve 34 . guinlerde tek. $25,26,27,2829,30$ ve 31. günlerde isc uygulama öncesi ve 1 saat sonrası olmak ize:e iki kez kan alınd. Grup V'ten doğumu izleyen $15,18,33$ ve 34 . günlerde tek ve 31. günde uygulama öncesi ve 1 saat sonrası olmak ï\%erc $2 \mathrm{kc} \%$ kan alınd. Alınan kan örneklerinden elde edilen serumlar çalışma sonunda hormon analizlerinin yapılacas̆ Lalahan Hayvan Sağlığı Nüklcer Araştırma Enstitüsii Fizzyoloji Laboratuvarma iletilmek ïzere $-20^{\circ} \mathrm{C}$ de saklandı. Kan progesteron dïzcyleri Marcus ve Hacketl (30)'in bildirdiø̧i EIA yöntemi ile ölçüldii.

Çalışmaya alınan inekler sặım sonrası çıkıkları padoklarda sabah ve akşam olmak izere gunde iki defa izlendi. Östruslar tohumlama öncesi rektal mulyene uygulamasıyla ovaryumdaki yapilarm incelenmesiyle doğrulandı. Otu\% dördüncï günden sonra östrus gösteren inekler suni tohumlama yoluyla tohumland. Çeviren hay. vanlarda en fazla 3 tohumlama yapildı. Gebelikler tohumlana sonrası 45. günde yapilan rektal muayene sonuçlarna göre tespit edildi. ilde edilen sonuçlara göre; buzağılama ilk-östrus aralı̆̆ı, buxağılama-gebe kalma aralığı, her gebelik için gereken tohumlama salyısı ve gebe kalnı oranları gibi fertilite parametreleri izerinde değerlendirmeler yapıldı.

Istatistiksel analizler student t-test yöntemine göre yapild1.

\section{Bulgular}

Calışmada elde edilen bulgular Grup I (Kontrol). Grup II (GnRH+bctanimctik+PGF2a). Grup III (GnRH+ $\mathrm{PGF}_{2} \alpha$ ), Grup IV (GnRH+betamimetik+hetablokör), Grup V (GnRH+betablokör) ayn ayrı deģerlendirilnų ve sonuçlar Şckil l'de birleştirilerek sunulmuş̧ur. Flde edilen reproduktif parametreler Tablo $2^{\circ}$ de sunulmuştur.

Tablo 1. Gruplarda ilaçların uygulama zamanları.

Table I. Application time of the drug according to groups.

\begin{tabular}{ccccc}
\hline Ginler & \multicolumn{4}{c}{ Gruplar } \\
\cline { 2 - 5 } & Grup 2 & Grup 3 & Grup 4 & Grup 5 \\
\hline 15 & GnRH & GnRH & GnRH & GnRH \\
25 & BM & & BM & \\
26 & BM & & BM & \\
27 & BM & & BM & \\
28 & BM & & BM & \\
29 & BM & & BM & \\
30 & BM & & BM & \\
31 & PGF2 $\alpha$ & PGF2 $\alpha$ & BB & BB \\
\hline
\end{tabular}


Tablo 3'dc ise kullanılan çalışma gruplarında belirlenen zamanlarda kan progesteron değerleri sayısal olarak yansitilmaktadir.

Postpartum 25 ile 30. günler arasinda betaminetik (Bamethanc sulphate) uygulamasindan sonra kan progesteron değcrlerinde 60. dakikanın sonunda belirgin bir autuş saptannıs $(p=0.05)$ ve daha sonra uygulama öncesi seviyesine ulaşmişur. Postpartum 31. günde uygulanan helablokör (Propranolol) progesteron değerini $2.37 \pm$ $0.27 \mathrm{ng} / \mathrm{ml}$ 'den 1. saatin sonunda $1.45 \pm 0.32 \mathrm{ng} / \mathrm{ml}$ 'ye düşürmuïş 1. saatin sonunda tekrar uygulama öncesi seviyesinc yükselerek bu yüksselişini sürdürniiş̧ür

Uygulama sonrası ikinci giinde (pp 33. gün) progesteronun tekrar uygulama öncesi duizeyine yakın bir düzeye $(2.43 \pm 0.63)$ yükseldiği ve bu artışını pp 34 . günde de sürdürdüğ gi gö/lenmiştir.

\section{Tartışma ve Sonuç}

Modern sütçü yetiştirmelerde postpartum dönem, fertilitenin sürekliliğ̣ yönünden oldukça önemlidir. Postpartum dönemde ortaya çlkan ve sıkça rastlanılan sakin kı/gnnlık, uterus enfeksiyonları gibi patolojik olgularm ortadan kaldırılmasının yamsıra, klinik açıdan önem tasyjan uterus involiisyonunun ve ovaryum aktivitesinin hizlandrrlması ve gozzlenebilir ostruslarm daha erken bir dönende başlatılması verimlilik ve ekonomi açısından ar\%u edilen $\ddot{z} z$ elliklerdir.

Vormal doğum yapmış incklerde doğum-ilk östrus arasındaki süre sütçü ineklerde 30-76 gün, etçi ineklerde isc 4()-68 güun olarak bildirilmiştir $(4,15,38,43)$. Kamimura ve ark. (17), ulırasonografi ile yaptığı çalışmada postpartum ilk östrusu $21.7 \pm 7.3$ gün olarak saptamıştır. Çalışmada, kontrol grubundaki hayvanlarda buzağllama-ilk östrus arası sürc $41.22 \pm 15.53$ gün olarak hulunnuşlur. Bu bulgu, kontrol grubuyla yukarsda helirtilen araşturıcilarm bulguları arasında bir benzerlik olduģ termektedir.

Çalışmada doğum sonrası GnRH+betannimetik+ $\mathrm{PGF}_{2} \alpha$ uygulanan 10 inektc burağllama-ilk östrus aras! süre postpartum 32-37. günler arasinda orlalama 33.66 \pm 1.41 gün olarak bulunnuştur. Bu bulg̨u kontrol grubu ile karşllaşturıldığında 7.5 günlük bir kısalma göstermiş̧ir. Bulgular araştıricıların $(4,15.38 .43)$ normal ineklerde belirttikleri 30-76 gün sınırları içerisinde kalmakladır. Çalışmada minimal sınıra Grup II'de yaklaşılnuşsur.

Araştırıcılar $(9,14,31,33,45)$, homon preparaltarının uygulandığı gruplarda buza ̌́lama-ilk östrus arasındaki sürcnin kısalacağını vurgulamışlar ve çalışmada da bu bulgulara benzer sonuçlar elde edilmiştir.

Vural (48), postpartum 14. guinde GnRH, bunu takip cden 10 . günde $\mathrm{PG} \mathrm{F}_{2} \alpha$ uygulamasmn buzağlama-jlk östrus aralığını önemli ölçüde kısaltığını helirtmişı ir

Grup II'de en düşiik buzağ̀lama-ilk östrus aralığımm elde edilmesinin nedeni birçok araşurıcınun belirtliğ ğibi $(2,35,40,44,46)$ betamimetik etki yapan ilaçlar tarafından adenilat siklaz enziminin aktive edilmesiyle progesteron salmumundaki aruş ve bu nedenle de izleyen östrus beldeklerinin daha belirgin olmasına bağlanabilir

Grup IV'de buzağılama-ilk östrus aralığımın uzun olmasinin nedeni ise betamimetiklerin progesteronu artturmalarına karşın $(2,35,40,44,46)$, betablokörlerin progesteron hormonunu azaltmalarına rağmen $(16,26.49,50)$ $\mathrm{PGF}_{2} \alpha$ kadar yeterli bir luteolizise neden olmamalarıdir.

Araşurıcilar $(1,3,32.34,4$ ! $)$, postpartun dönemde patolojik olgu göstermeyen incklerde buzağlama-lckrar

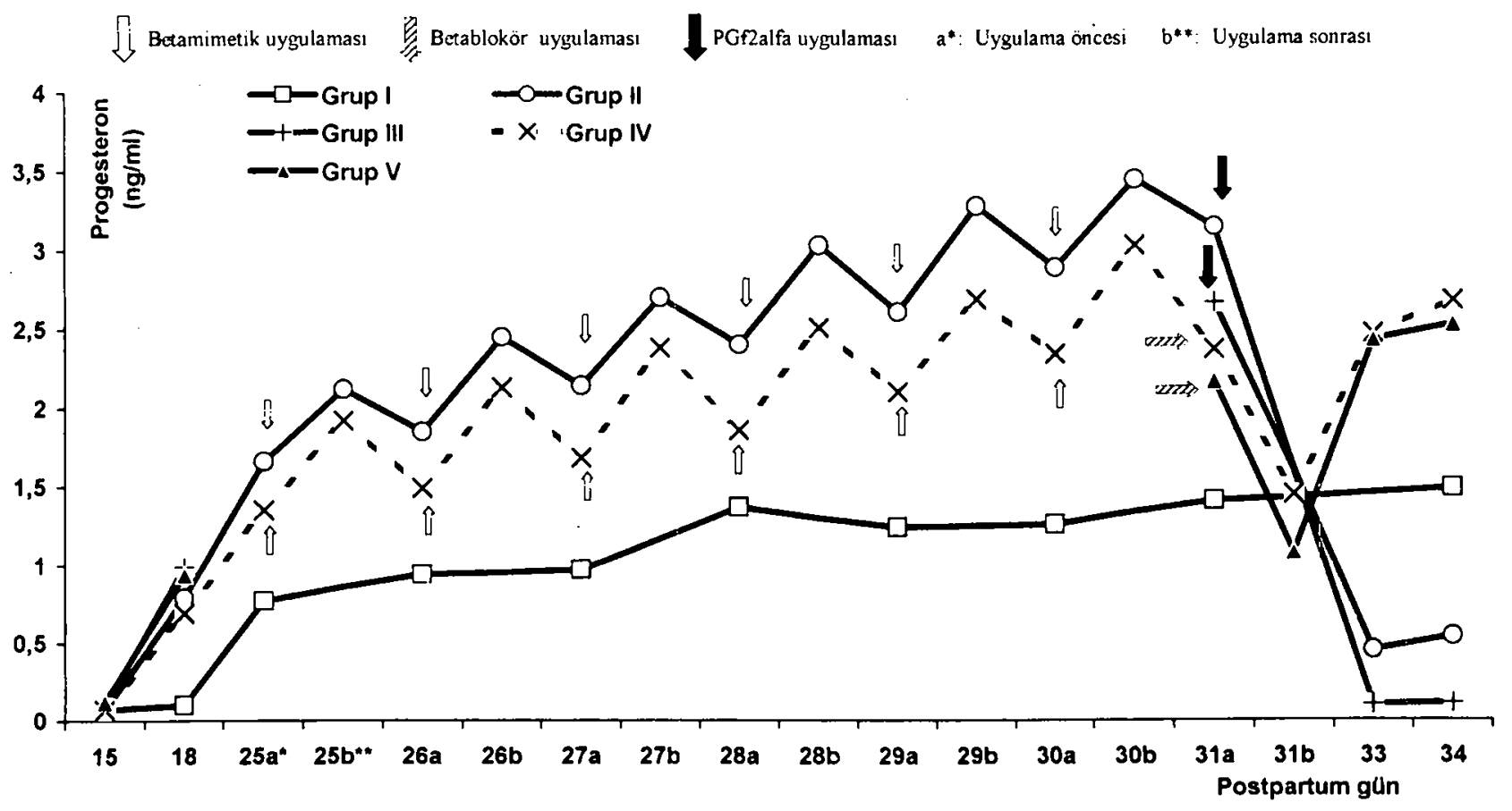

Sckil I. Gruplata görc kan progesteron deţerleri ve yapılan uygulamalar.

Figure 1. Drug application times and blood progesterone levels according to groups 
Tablo 2. Reproduktif parametrcler.

Tatble 2. Reproductive parameters.

\begin{tabular}{|c|c|c|c|c|c|}
\hline Paramctreler & $\begin{array}{c}\text { Grup I } \\
\text { (Kontrol. } \mathrm{n}=10 \text { ) }\end{array}$ & $\begin{array}{l}\text { Grup II } \\
(n=10)\end{array}$ & $\begin{array}{l}\text { Grup III } \\
(11=10)\end{array}$ & $\begin{array}{l}\text { Grup IV } \\
(n=10)\end{array}$ & $\begin{array}{l}\text { Grup IV } \\
(n=10)\end{array}$ \\
\hline \multicolumn{6}{|l|}{ Buzalğllama - jlk } \\
\hline östrus aralı̆̆g (giin) & $41.22 \pm 1.5 .53$ & $33.66 \pm 1.41$ & $33.75 \pm 0.46$ & $39.33 \pm 3.35$ & $37.22 \pm 1.20$ \\
\hline \multicolumn{6}{|l|}{ Buzaglama - gebe } \\
\hline kalma arallğ (g(in) & $59.7 \pm 29.2$ & $5(1) .87 \pm 12.3$ & $52.75 \pm 1.3 .78$ & $57.86 \pm 14.48$ & $64.13 \pm 18.57$ \\
\hline \multicolumn{6}{|l|}{ Her gebelik için } \\
\hline tohumlama satyssi & $1.75 \pm 0.88$ & $1.87 \pm 0.64$ & $1.87 \pm 0.64$ & $2.0 \pm 0.81$ & $2.25 \pm 0.88$ \\
\hline Cicbe kalmat oratוo & $8 / 10$ & $8 / 10$ & $8 / 10$ & $7 / 10$ & $8 / 10$ \\
\hline (3 tohumlamat sonrast) & $\% 80$ & $\% 80$ & $\% 80$ & $\% 70$ & $\operatorname{cir} 80$ \\
\hline Ilk tohumlitmatda & $4 / 10$ & $2 / 10$ & $2 / 10$ & $2 / 10$ & $2 / 10$ \\
\hline gebe kalma oramı & $\% 40$ & $\% 20$ & $\% 20$ & $\% 20$ & $\% 20$ \\
\hline Ikınci tohumlamada & $2 / 6$ & $5 / 6$ & $5 / 6$ & $3 / 6$ & $2 / 6$ \\
\hline gebe kalma orann & $\% 33.33$ & $\% 83.3$ & $\% 83.3$ & $\% 50$ & $\% 33.33$ \\
\hline Úçiuncij tohumlamada & $2 / 4$ & $1 / 4$ & $1 / 4$ & $2 / 4$ & $4 / 4$ \\
\hline gebe katma oram & $\% 50$ & $\% 25$ & $\% 25$ & $\% 50$ & $\% 100$ \\
\hline
\end{tabular}

Tablo 3. Kall progesteron de gerleri.

Table 3. Blood progesterone values

\begin{tabular}{|c|c|c|c|c|c|}
\hline & Grup I (Kontrol) & Grup II & Grup III & Grup IV & Grup V \\
\hline 15 & $0.07 \pm 0.02$ & $0.07 \pm 0.01$ & $(0.09 \pm 0.07$ & $0.07 \pm 0.013$ & $0.12 \pm 0.019$ \\
\hline 18 & $(0.10 \pm 0.10$ & $0.79 \pm 0.13$ & $0.99 \pm 0.10$ & $0.69 \pm 0.15$ & $0.94 \pm 0.10$ \\
\hline $25 \mathrm{a}^{*}$ & $0.77 \pm 0.62$ & $1.66 \pm 0.25$ & & $1.35 \pm 0.23$ & \\
\hline $25 b * *$ & & $2.12 \pm 0.30$ & & $1.92 \pm 0.22$ & \\
\hline $26 a$ & $0.94 \pm 0.59$ & $1.85 \pm 0.32$ & & $1.49 \pm 0.21$ & \\
\hline $26 b$ & & $2.45 \pm 0.33$ & & $2.13 \pm 0.23$ & \\
\hline $27 \mathrm{a}$ & $0.97 \pm 0.64$ & $2.14 \pm 0.42$ & & $1.68 \pm 0.24$ & \\
\hline $27 \mathrm{~b}$ & & $2.70 \pm 0.38$ & & $2.38 \pm 0.30$ & \\
\hline $28 \mathrm{a}$ & $1.37 \pm 0.70$ & 2.4()$\pm(0.50)$ & & $1.86 \pm 0.27$ & \\
\hline $28 \mathrm{~b}$ & & $3.03 \pm 0.43$ & & $2.51 \pm 0.36$ & \\
\hline $29 \mathrm{a}$ & $1.24 \pm 0.72$ & $2.61 \pm 0.55$ & & $2.10 \pm 0.35$ & \\
\hline $29 \mathrm{~b}$ & & $3.28 \pm 0.52$ & & $2.69 \pm 0.35$ & \\
\hline $300_{\mathrm{al}}$ & $1.26 \pm 0.78$ & $2.89 \pm 0.62$ & & $2.34 \pm 0.38$ & \\
\hline $30 \mathrm{~b}$ & & $3.45 \pm 0.78$ & & $3.0 .3 \pm 0.39$ & \\
\hline $31 \mathfrak{a t}$ & $1.41 \pm 0.77$ & $3.15 \pm 0.68$ & $2.67 \pm 0.48$ & $2.37 \pm 0.27$ & $2.17 \pm 0.47$ \\
\hline $3 \mathrm{lb}$ & & & & $1.45 \pm 0.32$ & $1.08 \pm 0.35$ \\
\hline 33 & & $0.45 \pm 1.10$ & $0.10 \pm 0.08$ & $2.47 \pm 0.38$ & $2.43 \pm 0.63$ \\
\hline 34 & $1.49 \pm 0.72$ & $0.54 \pm 1.08$ & $0.11 \pm 0.12$ & $2.68 \pm 0.89$ & $2.53 \pm 0.80$ \\
\hline
\end{tabular}

$\mathrm{a}^{*}:$ Ilaç uygulamadlan hemen önce.

$b^{* *}$ : Ilaç uygulamadan bir saat sonra.

$a^{*}:$ : Before the drug infusion.

$b^{* *}$ : Onc hour after the drug infusion.

gebe kalma aralığının 60-100 gün arasında olması gerektiģini bildirmektedirler. Çalışmada kontrol grubu olarak alınan grupta buzağılama-tekrar gebe kalma aralığı $59.7 \pm 29.2$ gün olarak bulunmuştur. Bu olgu araştırıcıların belirttiği günden az bulunmuştur. Çalışmada Grup III'de de buzağılama-gebe kalma aralığının kontrol grubuna oranla daha kısaldığı gözlenmiştir. Bu da araşurıcıların (6.42) sonuçları ile paralcllik göstermiştir. Çalışma grupları arasında en duişük buzăğılama-gebe kalma aralığına sahip olan Grup II'de uygulanan betaadrenomimetik ilacm (Bamethane sulphate) utcrus involüsyonu üzerine olan olumlu etkisi araşuricıların (10,39.52) bulguları ile paralellik göstermiştir. Araşurıcılar yaptıkları çalışmalarda betaadrenomimetik ilaçlarm utcrus involüsyon oranlarm etkilediğini (22) ve ovaryum iizcrindeki yap1larn fonksiyonlarmı destekleyerek gebe kalma sürelerinde kısalmalara neden ola- bileceklerini bildirmektedir. Kesler ve ark. (21). $\beta$-antilgonistlerin fertilite üzerine etkisini araşurmıs ve bu fil lışmasında postpartum ilk tohumlama zamanında yapılan tedavilerde sonuçların iyi olmadığını ve buzağ kalma aralığının uzadığını, tohumlamayı takip eden hetablokör uygulamalarnnda daha iyi gebelik elde edildiğgni bildirmcktedir.

Betablokör uygulanası sonrasundia luteal regresyon zamanında bir değişikliğe rastlanmadığını ve bunun so nucunda ovulasyonların görülmediğini belirterck. bu. zağılama-gebe kalma aralığının uzayabileceğini vurgulanmıştır $(5,12,29)$. Çalışmada, V. Grup içerisinde bu araştırıcıların bulguları ile benzer sonuçlar elde edilmiş̧ır.

Reproduktif parametre olarak kabul edilen, her gebelik için gereken tohumlama saylları, kontrol grubu ite karşılaştırıldığında diğer gruplarda belirgin hir artış gös. termiştir. Sonuçlar Kesler ve ark.'nın (21) belirttiğ post- 
partum ilk tohumlamada $\beta_{2}$-antagonistlerinin iyi sonuç vermediğ bulgusu ile paralellik göstermiş̧lit.

Kesler ve ark. (21), betablokör veya GnRH sağıtımundan sonra daha yuiksek oranda gebelik elde etmişlerdir. Çalışnada IV. Grup içerisinde GnRH+betamimetik+betablokör'lerin birlikte kullammları nedeni ile bu orammn daha diişük olduğu kanısına varılmuşur.

Çalışnada hormon uygulamalarından sonra metritis ve lohumlama öncesi anöstrus gibi reproduktif problemlerin ortaya çıktığı gö̌lenmiştir. Bulgular, e:ken oostpartum dönende ovaryum aktivitesinin uyanlması için yapilan GnRH uygulaması sonucunda bu tür reproduktif problemlerin çıkabileceğ bulguları ile $(7,8,11,19.24) \mathrm{pa}$ ralellik gösterniş̧ir.

Proslaglandin $\mathrm{F}_{2} \alpha$ uygulaması sonrasında kan progesteron seviyesi süratle dïşen bu gruptaki inckler östrus gostermişlerdir. Araştırıctlar $(5,25,26,29)$ betamimetik uygulamasindan sonra kan progesteron düzeyinde belirgin bir artıßın olduğunu, ancak bu artışların 1 saal içerisinde düştiğüinii fakat devamlı uygulanması halince bu artı̧̧ların devam ettiğini bildirmişlerdir. Bu 'illgilerie II. Grupta elde edilen bulgular arasında paralellik göriilinekledir.

Wheeler ve ark. (49), koyunlarda bciablchicilerin

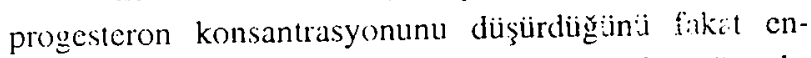
jeksiyondan sonraki 70 dakika içerisinde bu düşiı̧̧ï tekrar enjeksiyon öncesi düzeyine ulaştı̆̆ın vtirgulamakıadır. Aynı araşurıcı, betablokörlerc bağlı ola:ak progesteron konsantrasyonunda meydana geien azalnamm ovulasyonun sempatik stimülasyonu sonucunda olduğunu da belirtmektedir. Kotwica ve ark. (26), betablokörlerin siklusun luteal evresinde kullanıldığında progesteronda meydana gelen diişiişuin siklus süresini etkilemediğini belirtmektedir. GnRH+betamimetik+betablokör uygulanan IV. Grupta isc progesteron düzeyleri II. Grupla benzerlik göstermiştir. Bu bulgular araşturıcıları" belirttiği verilere (26.49) benzerlik göstermiştir.

Bctabloköricrin $\mathrm{PGF}_{2} \alpha$ kadar progesteron değgerlerinde düşüşe neden olmadığı görülmektedir. Betablokörlerin progesteron miktarını diiş̧ïmelerine rağmen $70 \mathrm{da}-$ kika içerisinde tekrar yuiksclmesi ile Lutcolitik aktivitesinin olmadığı belirtilmiştir (26). Bu: bulgular, çalışma bulgularıyla paralellik göstcrmiştir.

Betablokörlerin ovaryum üzerinde artmı̧ progesteronu düşümelerine karşın östrusların oluşmiasına neden olacak kadar bir luteolizis meydana getirmediği $(16,25,26.49,50)$ çalışmal bulgulariyla paralellik göstermiștir.

Sonuç olarak, çalışmada elde edilen bulgulara göre postpartum dönemin 15. gününde GnRH uygulamasm takiben uygulanan betamimetik enjeksiyonları - ve belamimetik enjeksiyonlarm izlcyen 2. günün sonunda yapılan $\mathrm{PGF}_{2} \alpha$ enjeksiyonlarmnn postpartum dönemde burağılama-1lk östrus, buzağlama-tckrar gebe kalma ara- lığını kısaltmaları, reproduktif fertiliteyi arturmaları nedeniyle kullanılabilir bir yöntem olduğu; huna karşın be lablokörlerin gerek GnRH gerekse GnRH+betamimelik enjcksiyonlarından sonra kullanılmasının doğun somrası fertilite üzerine önemli bir etkisinin olmadığı kanısma varilmıştur.

\section{Kaynaklar}

1. Nlaçam E (1994): Evcil Hayvanlarda Reprordieksiyon Sunt Tohumlama ve Infertilite. 1. baskı. Nurol Matbalacilık. All kara.

2. Ariens EJ, Simonis AM (1983): Physiolegical and pharmacological aspects of adrenergic receptor classification. Biochem Pharmacol. 32, 1539-1545.

3. Arthur (GH, Noakes DE, Pearson H (1989): Veterinary Reproduction and Obstetrics (Theriogenology. $6^{\text {th }} \mathrm{cd}$. Batillicre Tindatl. London.

4. Bastidas P, Troeniz J, Verde O, Silva O (1984): Lfffect of restricted suckling and ovarian activity and kterthe involution in Brahman cows. Theriogenology. 21. 525531.

5. Battista P.J, Poof JP, Deaver IDR, Condon WA (1987) Biogenic amine regulation of bovine luteal prosesterone production in vivo. J Reprod Fert. 80. $517-522$.

6. Benmrad M (1985): Orulation, estrous and fertility traits of dain cows after early rostpartum tratment with sonadotropin releasing hormone and proskaskandin $F_{2} \alpha$ Diss Abstr Int, 46. 7-B

7. Bostedt H, Peche E, Strobl K (1980)): Zur auswirkun: Frihzeitig Post Partum Verabreichter GnRH-Gaben auf Puerperalverlauf und Konzeptionsergebnis bei Kishen nach Retentio Secundinarum. Berl Munch Ticrartz.l Wschr, 90. 184-188.

8. Etherington WG, Martin SW, Cole JF (1984): The effect of GnRH and/or cloprostenol in the postpartun daing cows. A field trial. Proc. Xth Int Cong Anim Reprod and AI. Urbana-Champaign, I. 317

9. Etherington WG, Martin SW, Dohoo IR, Bosu WTK (1985): Inter-relationships between postpartum events. hor monal theraps reproductive abmormalities and reproductive performance in dairy cows: A path analysis. Cann J Comp Med, 49, 261-267.

10. Ford SP, Reynolds I.P (1983): Role of adrenergic receptors in mediating estradiol $17 \beta$ stimulated increases in uterine blood flow of cows. i Anim Sci, 57 665-672.

11. Frecdman S (1994): Horinomal therapy in retained placenta and postparturient inetritis. Isracl J Vol Mcd. 49. 17 19.

12. Gadsby JE, Keyes Pl, Schwar T (1985): Do catecholanines play a physiologic role in regulating corpus luteum function in the pseudopregnant rabbit?' Biol Rcprod, 32, $9017-915$

13. Gerber G.J, Nies SA (1985): Befa-adretierzic blocking" drug.s. Ann Rev Med. 36, 145-164.

14. Humprey WD, Kaltenbach CC, Dunn TK; (1983) Cha racterization of hormonal patterns in the heef con during postpartum anestres. J Anim Sci, 56. 445-453

15. Hussain AM, Daniel RCW (1991): Borine nermal (and abnormal reproductive and endocrine functions daring the postpartum period: A review. Rcprod Dom Auim, 26. 101111. 
16. Jordan WA, Caffrey JI, Niswender. GD (1978): Catecholamine-induced stimulation of progesterone and adenosine 3'.5'-monophosphate production hy dispersed ovine luteal cells. Endocrinology. 103. 385-392.

17. Kamimura S, Ohgi T, Takahashi M (1993): Postpartum resumption of orarian activity and uterine involution monitored by ultrasonography in Holstein cows. J Vet Med Sci, 55. 643-647.

18. Kannisto P, Owman C, Walles B (1985): Involvement of Incal adrenergic receptors in the process of ovulation in sonadotropin-primed immature rats. J Reprod Fert. 75. 357-362.

19. Kayaalp O (1983): Rasyonel Tedavi Vönünden Tibbi Farmakoloji. 2. baskı. Cill 3. Ulucan Matbaası, Ankara.

20. Kayaalp (O (1985): Rasvonel Tedavi Yönünden Tabhi Farmakoloji. 3. bask ı. Cilt 2. Ulucan Matbaası, Ankara

21. Kesler DJ, Elze K, Görlach A (1994): Zum Einfluß von GnRH, HCG und $\beta_{2-\text { antagonisten auf die konzeptionstate }}$ beim Rind. Ergebnisse einer Feldstudie. 27.Jahrestagung uher Physiologie der Fontpflanzung. Berlin. Reprod Doincstic Anim. 29, 249.

22. Kesler DJ, Troxel TR, Hixon DI (198()): Effect of dals postpartum and oratian changes in postpartum suckled beef con:s. Theriogenology, 13.287-296.

23. Kitaa JMA, Mitema LS (1994): Effects of antiarhythmic drugs. (Verapamil, Propranolol. and Lignocaine) on the electrocurdiogram and haemotology in Adrenaline-induced arthythmias in dogs ancesthetized with Halothane. Br Vet J. 150. 365-376.

24. Korematsu K, Takagi E, Kawabe T (1993): Therapeutic effects of Moxihustion on delaved uterine involution in postpartum dairy cows. J Vel Med Sci. 55. 613-616.

2.5. Kotwica J, Skarzynski D, Jaroszewski J (1990): The coccyseal artery as a route for the administration of drugs into the reproductive tract of catle. Vet Rec, 127, 8-40.

26. Kotwica J, Skarzynski D, Jarosıewski J (1991): Involvement of b-adreno receptors in the regulation of luteal function in cattle. Br Vet J. 147. 89-196.

27. Kotwica J, Skarzynski D, Jaroszewski J, Bogacki M (1904): The secretory function of corpora luted stimulated by noradrenaline in cattle is not affected by proslaglandins. 27. Jahrestagung ïher Physiologie der Fortpflenzung, Berlin. Reprod Domestic Anim, 29. 255.

28. Kotwica J. Skarzynski D, Jaroszewski J, Kotwica (; (1991): l:ffect of $P G F_{2} \alpha$ analogue on orarian orytocin and progesterome release in heifers: catecholamines are not inwolled in this process. Anim Reprod Sci. 25. 1-10).

29. Luck MR, Jungclas B (1987): Catecholamines and ascorbic acid as stimulators of bovine ovarian oxytocin secrefirm. J Endocr, 114. 423-430.

30). Marcus G.J, Hackett A.J (1986): Use of enzyme linked immunosortbent assay for measurement of bovine serum and milk progesterone without extraction. J Dairy Sci, 69.818824.

31. Martinez J, Thibier M (1984): Fertility in anoestrous dary cows following treatment with prostaglandin $\mathrm{F} 2$ alfa or the symthetic: analogue fenjrostalene. Vet Rec. 21. 5759.
32. McDonald LJ: (1980): Veterinury Findocrinoleg: and Reproduction. 3rd ed. Bailliere Tindail. London.

33. Mcleod B., Dodson SE, Peters AR, Lamming GE

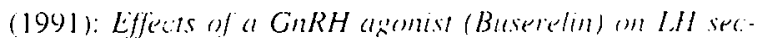
retion in postpartum beef cons. Anim Reprod Sc1. 24. 1-11

34. Morrow DA. (1980): Current Therapy in Thermsendes: lst ed. WB Satunders Co. Philadelphia

35. Norjavaara $Z$, Rosberg $\mathbf{S}$, Gafvels $M$, Boberg BM, Sclstam (; (1989): $\beta$-adrenergic receptor concentration and subtype in the corpus lutetim of the adult preudopresintmint rat. J Reprod Iicrt. 86. 567-575.

36. Norjavaara E, Rosberg S, Gafvels M. Selstam (; (1984): fis adrenergic receptor concentration in corporal lutect of ditferent ages obtained from tresnamt mare serwm sosnadotropin- treated rats. Endocrinology. 114, 2154-2159

37. Norjavaara E, Selstam (;, Damber .JE, Johansson BM (1983): In vivo effect of noradiencline on the crelic AMP level in rat corpora lutea. Acta Physiol Scand. 119. 113116.

38. Paisley I, G. Mickelsen WD. Anderson PBB (1980): Mechanisms and therapy for retained fotal methloranes and aterine infectious of cons: A review. Theriogenology. 25. 353 381

39. Pennefather N.J, Paull D.J, Story ME, Zicconc SP (1993): Super-sensitivity of the sumulant action of noradrenaline and haman myometrium near trim. Reprod Fertil Dev, 5, 39-48

40. Perkins SN, Cronin M.J, Veldhuis JD (1986): Properties of B-adrenergic receptors on porcine corposal luted and gramulosa cells. Endocrinology. 118. 999-10015.

41. Rawson CL, (1986): Reproductive Management of Sinall Dairy Farms. 390-394. In: DA Morrou (Ed). Current therapy in Theriogenology. $2^{\text {n.l }}$ ed. WB Situnders Co. Phi ladelphia.

42. Richardson GF, Archbald LF, Galton DM, Godke RA (1983): Efffect of Goncadotropin-teleasims hormone and Prostaglandan $\mathrm{F}_{2} \alpha$ on reproduction in postpartum darr? cows. Theriogenology. 19, 763-768.

43. Koherts JS (1991): Veterinary Obstatrics and (jental D)i seases (Theriogenology. 3rd ed. Edwatrds Brothers Inc. Michigan.

44. Schmidt (i, Owman C, Sjöherg NO. Walles B (1985) liffuence of adreno-receptor agomists and antaponists on orulation in the rabbit orary perfiesed in ritro. J Alton Pharmaic. 5. 241-250).

45. Short RE, Bellows RA, Staigmiller RB, Berardinelli JG; Custer EE (1990): Physiological meshanism. comtrollin: anestrus and infertiling in post-partum beef cante. J Anim Sci, 68, 799-816

46. Spicer LJ (1986): Catecholaminersic regulation of orarian function in mammals: corrent concepts. Mini review Life Sci. 39, 17()1-1711.

47. Thomas AP (1987): Elfects of intratterine infections an the resumption of normal ovulatory activity in postpartum daing cows. Diss Abstr Int. 48. 1915-B

48. Vural R (1989): Sürçii Ineklerde lirken Postpartum Do nemde GnRH. PGF $\alpha$ Uygulamalarmm Reprodukilf Per-

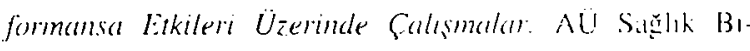
limleri Enstitiisii. Doktora Tc\%i. Ankitra. 
49 Wheeler AG, Lean J, Walker M (1988): Peripheral pro uesterme concentrations in the lateal phase ewe; effects of (is-adrenessic receptor antagonist and two $\beta_{2}$-adrenergic ugomists. J Endocr. 116, 137-142.

5) Wheeler A(;, Walker M, Lean J (1987): Influence of adrencenic: receptors on overian progesterone secretion in the pseudopregnant cat and oestradiol secretion in the aestrous c:at. J Reprod Fert. 79. 195-2(15.

5।. Widcus S, Randel RD, Humphrey WD (1987): Influence of repeated lon doses of gonadorropin releasing homone an postpartum interval and serum luteinizing hormonte in Brahman cross cows. Theriogenology. 27, 711-719
52. Zahradnik HP, Quaas L, Golle C (1984): The eftect of alpha and beta adrenergic modulation on prostaglandin ti beration $\left(P G E_{2}, P G F_{2} \alpha, P G I_{2}\right)$ in human sestational mor metrium. Acti Endocr Supp. 264, 73

\author{
Yazışma adresi: \\ Doç.Dr: Musstafa Kaymaz \\ AÜ Veteriner Fakilltest \\ Doğun ve Jinekoloji Anabolim Dall \\ 06110. Ankara \\ mkaymaz-(a) veterinary:ankara.edu.tr
}

